\title{
Anti-Bacterial Effect of Propolis Extract in Oil Against Different
}

\section{Bacteria}

\author{
Fatemeh Sadat Ghasemi, ${ }^{1}$ Seyyed Saeed Eshraghi, ${ }^{2}$ Fatemeh Andalibi, ${ }^{2}$ Hossein Hooshyar, ${ }^{3}$ Davood \\ Kalantar- Neyestanaki, ${ }^{4}$ Aniseh Samadi, ${ }^{5}$ and Mehdi Fatahi-Bafghi ${ }^{6,}{ }^{*}$ \\ ${ }^{1}$ Department of Parasitology, Pasteur Institute of Iran, Tehran, Iran \\ ${ }^{2}$ Department of Pathobiology, School of Public Health, Tehran University of Medical Sciences, Tehran, Iran \\ ${ }^{3}$ Department of Parasitology, School of Medicine, Kashan University of Medical Sciences, Kashan, Iran \\ ${ }^{4}$ Student Research Committee, School of Medicine, Kerman University of Medical Sciences, Kerman, Iran \\ ${ }^{5}$ Center for Research and Training in Skin Diseases and Leprosy, Tehran University of medical sciences, Tehran, Iran \\ ${ }^{6}$ Department of Microbiology, Faculty of Medicine, Shahid Sadoughi University of Medical Sciences, Yazd, Iran \\ "Corresponding author: Mehdi Fatahi-Bafghi, Department of Microbiology, Faculty of Medicine, Shahid Sadoughi University of Medical Sciences, Yazd, Iran. E-mail: \\ mehdifatahi@ssu.ac.ir
}

Received 2016 May 23; Revised 2016 August 16; Accepted 2017 March 08.

\begin{abstract}
Background: Propolis is one of the most potent natural antibiotics. Propolis as an active natural substance is attractive due to its antimicrobial properties. Propolis has been used in folk medicine for centuries. It is known that propolis possesses anti- microbial, antioxidative, anti-ulcer and anti-tumor activities. Therefore, propolis has attracted much attention in recent years as a useful or potential substance used in medicine.

Objectives: The purpose of this study was to verify the activity of an oily liquid extract of propolis that called propolis extract in oil against some Gram-positive and Gram-negative bacteria.

Methods: In this experimental study antimicrobial activity of oily liquid extract of propolis called propolis extract in oil with different concentration of ethanol, methanol and dimethyl sulfoxide as diluents against different bacteria species. The duration of study set up was from Nov 2014 to Sep 2015. Chi-Square and Kappa methods, using Open Epi and Graph Pad Prism Software (Graph Pad, San Diego, California, USA). Graphs were plotted by Microsoft Excel software.

Results: In the agar diffusion tests, using wells containing propolis suspension with methanol / dimethyl sulfoxide / ethanol per wells, the some of bacteria were most sensitive to the effect of propolis preparations. No growth inhibition zone was shown in the agar diffusion test with paper disks impregnate with methanol/ dimethyl sulfoxide suspension.

Conclusions: The evaluation of the examination results showed that the effectiveness of the extract against bacteria may be explained by the fact that the effect of oily propolis was statistically significant by the introduction of methanol and dimethyl sulfoxide.
\end{abstract}

Keywords: Antibacterial, Antibiotic Resistant, Propolis

\section{Background}

Propolis as an active natural substance [1] and one of the most potent natural antibiotics characterized by a very wide spectrum of effect [2]. Propolis natural character makes therapeutic application without inducing any antibiotic resistance or destroying useful flora [2]. There are two different major chemical compositions of propolis present including ethanolic extract and essential oil [3]. While oily propolis exhibited antibacterial activity against Staphylococcus epidermidis, Streptococcus pyogenes, Escherichia coli and Staphylococcus aureus [3, 4]. In vitro methods commonly used to evaluate the activity of propolis against Gram-positive bacteria [4]. Authors have mentioned that propolis inhibited the growth of Bacillus cereus and Staphylococcus aureus [5, 6]. Also Shigella sonnei is men- tioned as the most sensitive microorganism to propolis in the Gram-negative group and Streptococcus mutans [5] in the Gram-positive. The purpose of this study was to verify the activity of an oily liquid extract of propolis called propolis extract in oil (B Natural. Italy) against some Grampositive and Gram- negative bacteria. The difference of this study and similar researches is the oily form of propolis with methanol and dimethyl sulfoxide (DMSO) was affected on different bacteria.

\section{Methods}

This experimental study was performed in Department of Pathobiology, Tehran University of medical sciences, Tehran, Iran. 


\subsection{Propolis Preparation}

The oily liquid extract of propolis called propolis extract in oil (B Natural. Italy) examined in this research, was contained $30 \%$ of propolis and $70 \%$ soy seeds oil. This liquid propolis in different concentration of ethanol, methanol and DMSO as diluents was used. The bactericidal activity of this extract was analyzed by serial dilution from $10 \%$ to $90 \%$ in agar plate diffusion and $1 \%$ to $9 \%$ in serial dilution in microplate for minimal inhibitory concentration (MIC) determination [4]. The compositions of the dilutions were as follows: 10 (propolis oil 10\%, diluent 90\%) to 90 (propolis oil 90\%, diluent 10\%). Pure soy seed oil, methanol (Merck, Germany), DMSO and propolis oil (100\%) were used as control to test the inhibitory effect of the solvent [4]. Aseptic conditions was observed during the microbiological study and we determined the antimicrobial activity of the studied preparation, using disk on solid growth media, the well technique and tubes serial dilution [4].

\subsection{Serial Dilution in Tubes}

Serial dilution was carried out using sterile MuellerHinton broth (Merck, Germany) in order to obtain several concentrations between $1 \%$ to $10 \%$ of propolis extract per $\mathrm{mL}$ of broth [4]. The tubes were inoculated with $20 \mu \mathrm{L}$ of the bacteria suspension per $\mathrm{mL}$ of broth, homogenized and incubated at $37^{\circ} \mathrm{C}$ for 24 hours [4]. The minimal inhibitory concentration (MIC) was determined as the lowest concentration that will inhibit the visible growth of a microorganism after overnight incubation in the tubes [4].

\subsection{Microorganisms}

The bacteria with antibiotic resistant gene are more resistant to common antibiotics and these bacteria cause serious infections. In this study, the bacterial selection was performed in two antibiotic resistant and non- resistant groups' bacteria to compare the effect of solution. The following species were tested: Staphylococcus aureus ATCC 25923, Pseudomonas aeruginosa ATCC 27853, Escherichia coli

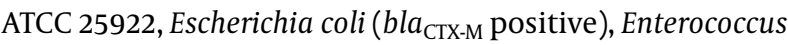
faecalis ATCC 29212, Pseudomonas aeruginosa (bla $a_{\mathrm{VIM}}$ positive), Shigella flexneri, Shigella sonnei, Pseudomonas aeruginosa PAO1, Klebsiella pneumoniae ATCC 700603, Escherichia coli MK148 (AmpC $\beta$-lactamase positive), Staphylococcus aureus $\mathrm{S} 1$ (SCCmec I positive), Staphylococcus aureus S3 (SCCmec III positive) and Pseudomonas aeruginosa (bla VEB $_{\text {positive). }}$ The Gram-positive and Gram-negative bacteria used in these tests were obtained from $24 \mathrm{~h}$ cultures and suspended in sterile saline solution to obtain concentrations of approximately $10^{8}[4], 10^{7}$ and $10^{5} \mathrm{CFU} / \mathrm{mL}[1,4]$. Resistance to preparations from natural material was examined in cultures of microorganisms in Mueller-Hinton agar
(Merck, Germany) [1]. The surface of the plates was inoculated using a sterile swab containing the suspension of bacteria in normal saline [4]. The cultures were incubated for 24 hours at $37^{\circ} \mathrm{C}$, and then the microorganism growth was evaluated [1].

\subsection{Antimicrobial Assay}

The following methods were used to evaluate the activity of the propolis extracts [4].

\subsubsection{Agar Plate Diffusion Tests, Using Paper Disks}

Sterile paper disks ( $6.0 \mathrm{~mm}$ ) containing different dilution of propolis extract (from $10 \%$ to $90 \%$ of propolis extract with ethanol, methanol and DMSO were put on three agar surfaces inoculated with different suspension diluents including $10^{8}, 10^{7}$ and $10^{5}[4]$. Each diluent with propolis was used in separate plate.

\subsubsection{Agar Plate Diffusion Tests, Creating Wells in Agar Plate}

Agar surface inoculated with different suspension diluents including $10^{8}, 10^{7}$ and $10^{5}$. Wells were formed in the agar surface and were filled with 40 to $60 \mu \mathrm{g}$ of studied preparation propolis in different diluents from $10 \%$ to $90 \%$ and dilutions as mentioned before (1). Agar wells were 6 $\mathrm{mm}$ in diameter [1].

\subsection{Statistical Analysis}

Statistical analysis was applied by Chi-Square and Kappa methods, using Open Epi and Graph Pad Prism Software (Graph Pad, San Diego, California, USA). Graphs were plotted by Microsoft Excel software.

\section{Results}

In this study no inhibition zone was seen for propolis dilution in ethanol as solvent. However any bactericidal effect was shown by methanol (Figure 1) and it is a good solvent for more consistent extraction of antimicrobial substances without antibacterial effect compared to other solvents including ethanol. So addition the methanol to propolis doesn't show anti-bacterial effect. In the agar diffusion tests using wells containing $60 \mu \mathrm{L}$ or $80 \mu \mathrm{L}$ of propolis suspension with methanol/DMSO per wells, growth inhibition within the wells was measured (Figures 3 and 4). The bacteria including Staphylococcus aureus ATCC 25923, Enterococcus faecalis ATCC 29212, Pseudomonas aeruginosa (PAO1) and Staphylococcus aureus S3 (SCCmec III positive) were most sensitive to the effect of propolis preparations (Tables 1 and 2). The minimal inhibitory concentration (MIC) of propolis oil was $0.8 \mathrm{mg} / \mathrm{mL}$ (0.8\%). Shigella flexneri and Shigella sonnei, as two resistant bacteria, were sensitive 
to propolis diluent in methanol but only Shigella flexneri was sensitive to propolis diluent in DMSO. The most resistance microorganisms to the studied preparations were Pseudomonas aeruginosa (bla $a_{\mathrm{VIM}}$ positive) and Pseudomonas aeruginosa (bla $a_{\mathrm{VEB}}$ positive) for methanol as diluent (Figure 5) and Pseudomonas aeruginosa (bla VEB $_{\text {positive) and }}$

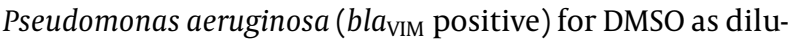
ent (Figure 6). For the agar diffusion test with wells, the propolis extracts with the largest growth inhibition zones were those extracted with $20 \%$ and $40 \%$ propolis with methanol. For propolis with DMSO, higher dose (about $40 \%-60 \%$ ) of propolis was needed for bactericidal effect. Most of the propolis with diluents (methanol or DMSO) testes showed greater growth inhibition zones than the pure oily methanol as control. The methanol and DMSO in the medium did not affect the growth of the strains during the experiments. The results of serial dilution in wells indicated that the bactericidal activity of the samples extracted with $20 \%$ and $60 \%$ propolis were the greatest, followed by those extracted with methanol and DMSO, respectively. The extracts obtained using pure propolis showed the weakest bactericidal activity. The inhibition of the growth of bacteria in the concentrations tested was not observed in the control wells containing only pure methanol and DMSO.

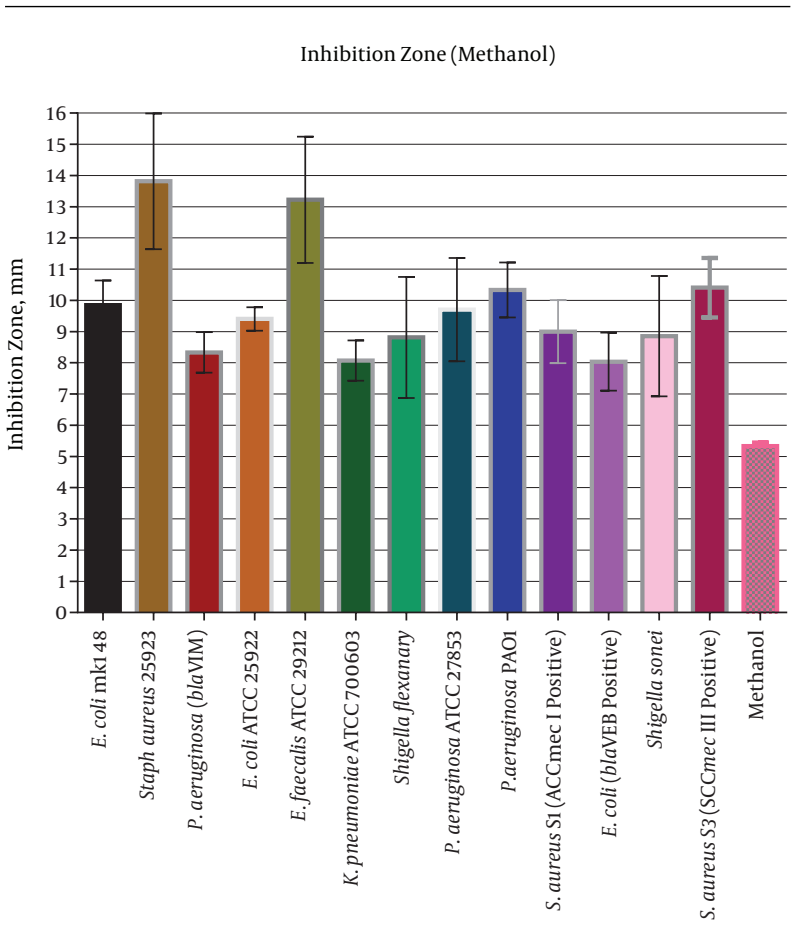

Bacteria

Figure 1. Mean of Inhibition Zone for Propolis and Methanol as Diluent

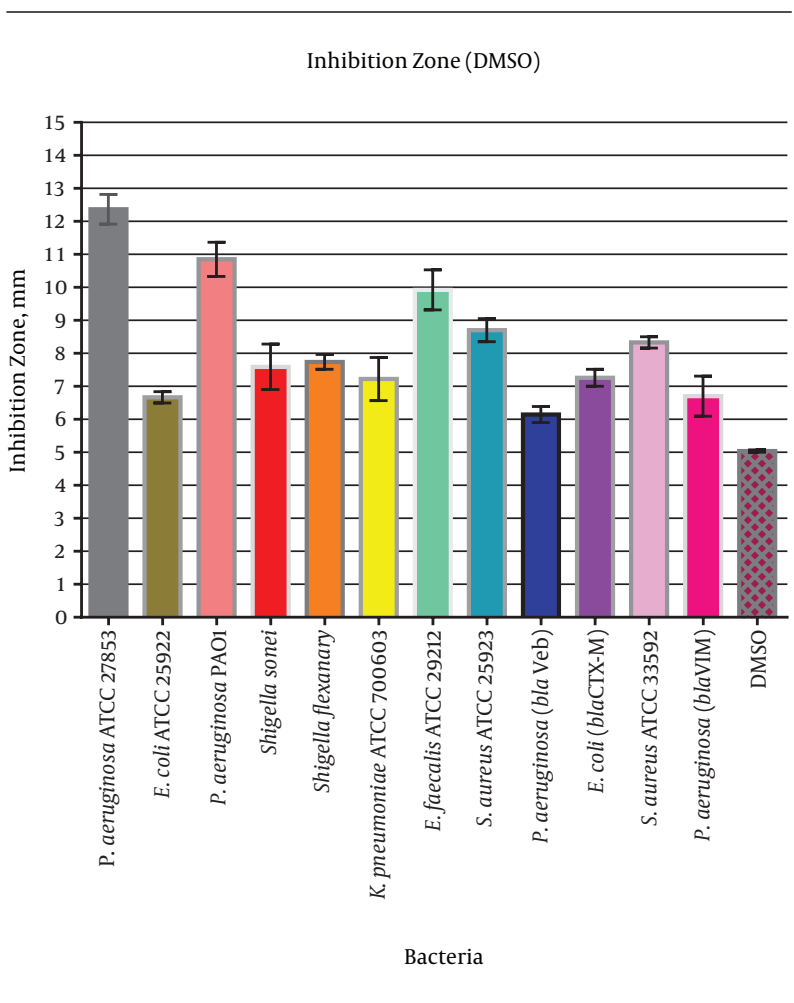

Figure 2. Mean of Inhibition Zone for Propolis and DMSO as Diluent

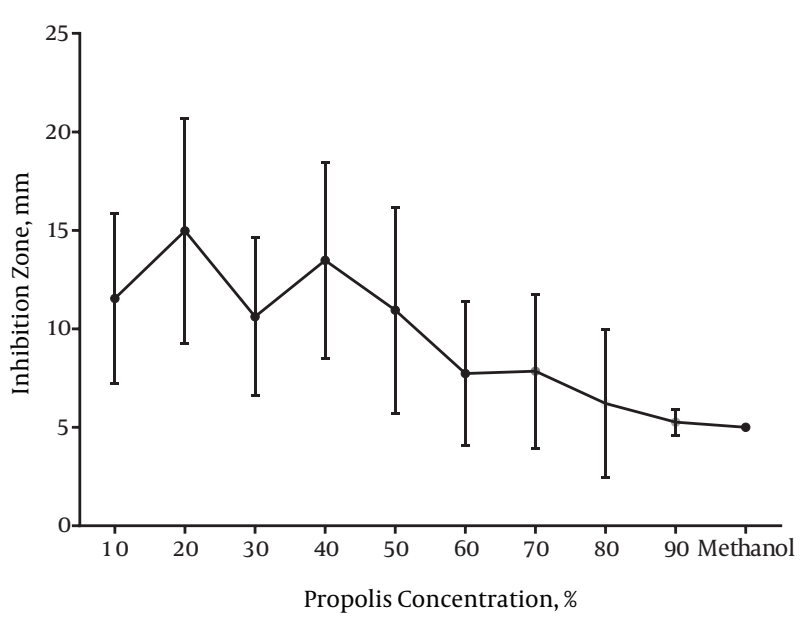

Figure 3. Inhibition Zone for Propolis with Methanol as Diluent in Different Concentrations from 10\% (10\% Propolis with 90\% Methanol) to 90\% (90\% Propolis with 10\% Methanol) and Pure Methanol as Control

\section{Discussion}

The results showed that the effectiveness of the extract against bacteria may be explained by the fact that the ef- 
Table 1. Bacteria Inhibitory Zone in $10^{8}, 10^{7}$ and $10^{5}$ Concentration Affected Propolis with Methanol as Diluent

\begin{tabular}{|c|c|c|c|c|c|c|c|c|c|c|c|c|c|c|}
\hline \multicolumn{2}{|l|}{ Bacteria } & \multirow[t]{2}{*}{ Total P Value } & \multicolumn{3}{|c|}{ Min } & \multicolumn{3}{|c|}{ Max } & \multicolumn{3}{|c|}{ Mean } & \multirow[t]{2}{*}{$10^{8}$ P Value } & \multirow[t]{2}{*}{$10^{7}$ P Value } & \multirow[t]{2}{*}{$10^{5}$ P Value } \\
\hline Species & Gram +1- & & $10^{8}$ & $10^{7}$ & $10^{5}$ & $10^{8}$ & $10^{7}$ & $10^{5}$ & $10^{8}$ & $10^{7}$ & $10^{5}$ & & & \\
\hline $\begin{array}{l}\text { Escherichia coli MK148 (AmpC } \beta \text {-lactamase } \\
\text { positive) }\end{array}$ & negative & $0.0497^{*}$ & 5 & 5 & 5 & 18 & 22 & 24 & 8.667 & 11.33 & 9.55 & 0.0815 & $0.0160^{*}$ & 0.0661 \\
\hline Staphylococcus aureus ATCC 25923 & positive & $0.0007^{* * *}$ & 5 & 5 & 6 & 14 & 5 & 9.5 & 18.11 & 11.11 & 12.22 & $0.0005^{* * *}$ & $0.0094^{* *}$ & $0.0021^{* *}$ \\
\hline Pseudomonas aeruginosa (bla $\mathrm{VIM}$ positive) & negative & 0.1327 & 5 & 5 & 5 & 11 & 18 & 24 & 7.33 & 8.11 & 9.55 & $0.0081^{* *}$ & 0.1080 & 0.0687 \\
\hline Escherichia coli ATCC 25922 & negative & $0.0024^{* *}$ & 5 & 5 & 5 & 17 & 12 & 15 & 9.89 & 8.66 & 9.66 & $0.0087^{* *}$ & $0.0083^{* *}$ & $0.0071^{* *}$ \\
\hline Enterococcus faecalis ATCC 29212 & positive & $0.0005^{* * *}$ & 8 & 5 & 5 & 25 & 20 & 22 & 17.22 & 11.78 & 10.67 & $<0.0001^{* * * *}$ & $0.0076^{* *}$ & $0.0358^{*}$ \\
\hline Klebsiella pneumonia ATCC 700603 & negative & $0.0391^{*}$ & 5 & 5 & 5 & 12 & 17 & 16 & 6.889 & 9.222 & 8.222 & 0.0779 & $0.0295^{*}$ & $0.0322^{*}$ \\
\hline Shigella flexneri & negative & $0.0113^{*}$ & 5 & 5 & 6 & 5 & 20 & 16 & 5 & 11.33 & 10.11 & 1.000 & $0.0221^{*}$ & $0.0015^{* *}$ \\
\hline Pseudomonas aeruginosa ATCC 27853 & negative & $0.0005^{* * *}$ & 5 & 5 & 5 & 5 & 15 & 23 & 7.11 & 12.78 & 9.22 & 0.1303 & $0.0027^{* *}$ & $0.0269^{*}$ \\
\hline Pseudomonas aeruginosa PAO 1 & negative & $0.0379^{*}$ & 5 & 6 & 5 & 14 & 20 & 29 & 9 & 12 & 10 & $0.0060^{* *}$ & $0.0034^{* *}$ & 0.0883 \\
\hline Staphylococcus aureus S3 (SCCmec III positive) & positive & $0.0002^{* * *}$ & 5 & 5 & 5 & 17 & 19 & 14 & 12.22 & 10 & 9 & $0.0002^{* * *}$ & $0.0107^{*}$ & $0.0076^{* *}$ \\
\hline Escherichia coli $\left(b_{l a}\right.$ CTX positive) & negative & 0.1729 & 5 & 5 & 5 & 11 & 25 & 12 & 7.22 & 9.88 & 7 & $0.0138^{*}$ & 0.0888 & $0.0486^{*}$ \\
\hline Shigella sonnei & negative & $0.0104^{*}$ & 5 & 5 & 5 & 5 & 20 & 23 & 5 & 10.89 & 10.67 & 1.000 & $0.0130^{*}$ & $0.0279 *$ \\
\hline Pseudomonas aeruginosa (bla $a_{\mathrm{VEB}}$ positive & negative & 0.1729 & 5 & 5 & 5 & 11 & 25 & 12 & 7.22 & 9.88 & 7 & $0.0138^{*}$ & 0.0888 & $0.0486^{*}$ \\
\hline Staphylococcus aureus S1 (SCCmec I positive) & & $0.0260^{*}$ & 5 & 5 & 5 & 12 & 20 & 14 & 7.11 & 10.56 & 9.33 & $0.0382^{*}$ & 0.0086 ** & $0.0053^{* *}$ \\
\hline
\end{tabular}

Table 2. Bacteria Inhibitory Zone in $10^{8}, 10^{7}$ and $10^{5}$ Concentration Affected Propolis with DMSO as Diluent

\begin{tabular}{|c|c|c|c|c|c|c|c|c|c|c|c|c|c|c|}
\hline \multicolumn{2}{|l|}{ Bacteria } & \multirow[t]{2}{*}{ Total P Value } & \multicolumn{3}{|c|}{ Min } & \multicolumn{3}{|c|}{ Max } & \multicolumn{3}{|c|}{ Mean } & \multirow[t]{2}{*}{$10^{8}$ P Value } & \multirow[t]{2}{*}{$10^{7}$ P Value } & \multirow[t]{2}{*}{$10^{5} \mathrm{PV}$ Value } \\
\hline Strain & Gram + - & & $10^{8}$ & $10^{7}$ & $10^{5}$ & $10^{8}$ & $10^{7}$ & $10^{5}$ & $10^{8}$ & $10^{7}$ & $10^{5}$ & & & \\
\hline Pseudomonas aeruginosa ATCC 27853 & Negative & $0.0065 *$ & 9 & 9 & 10 & 19 & 16 & 16 & 13.11 & 11.56 & 12.44 & $<0.0001^{* * * *}$ & $<0.0001^{* * * *}$ & $<0.0001^{* * * *}$ \\
\hline Escherichia coli ATCC 25922 & Negative & $0.0028^{* *}$ & 5 & 5 & 5 & 8 & 10 & 10 & 6.44 & 6.66 & 6.55 & $0.0006^{* * *}$ & $0.0357^{*}$ & $0.0384^{*}$ \\
\hline Pseudomonas aeruginosa ( $\mathrm{PAO1}$ ) & Negative & $0.0006^{* * *}$ & 6 & 7 & 9 & 13 & 15 & 14 & 10.33 & 10.33 & 11.89 & $<0.0001^{* * * *}$ & $<0.0001^{* * * *}$ & $<0.0001^{* * * *}$ \\
\hline Shigella sonnei & Negative & 0.1254 & 6 & 5 & 6 & 12 & 7 & 12 & 8.11 & 6.22 & 8.44 & $0.000^{* * *}$ & $<0.0001^{* * * *}$ & $0.0009 * * *$ \\
\hline Shigella flexneri & Negative & $0.0434^{*}$ & 6 & 5 & 5 & 11 & 10 & 11 & 7.77 & 7.33 & 8.11 & $0.0004^{* * *}$ & $0.0037^{* *}$ & $0.0019^{* *}$ \\
\hline Klebsiella pneumoniae ATCC 700603 & Negative & 0.4751 & 5 & 5 & 6 & 14 & 8 & 9 & 8.44 & 6.22 & 7.00 & $0.0013^{* *}$ & $0.0040^{* *}$ & $<0.0001^{* * * *}$ \\
\hline Pseudomonas aeruginosa (bla ${ }_{\mathrm{VIM}}$ positive) & & 0.1384 & 5 & 5 & 5 & 8 & 11 & 10 & 5.66 & 6.66 & 8.00 & 0.1501 & $0.0167^{*}$ & $<0.0001^{* * * *}$ \\
\hline Enterococcus faecalis ATCC 29212 & positive & $0.0023^{* *}$ & 6 & 6 & 6 & 16 & 12 & 12 & 11.11 & 9.55 & 9.11 & $0.0001^{* * *}$ & $<0.0001^{* * * *}$ & $0.0001^{* * *}$ \\
\hline Staphylococcus aureus ATCC 25933 & positive & $0.0001^{* * *}$ & 5 & 5 & 5 & 14 & 13 & 12 & 8.66 & 9.33 & 8.11 & $0.0037^{* *}$ & $0.0017^{* *}$ & $0.0053^{* *}$ \\
\hline Pseudomonas aeruginosa (bla $a_{\mathrm{VEB}}$ positive) & & 0.2939 & 5 & 5 & 5 & 7 & 11 & 10 & 5.66 & 6.33 & 6.44 & $0.0121^{*}$ & 0.0702 & $0.0293^{*}$ \\
\hline Escherichia coli $\left(\right.$ bla $_{\mathrm{CTX}}-\mathrm{M}$ positive $)$ & Negative & 0.1421 & 6 & 6 & 5 & 10 & 10 & 10 & 7.0 & 7.77 & 7.0 & $0.0003^{* * *}$ & $<0.0001^{* * * *}$ & $0.0085^{* *}$ \\
\hline Staphylococcus aureus ATCC 33592 & positive & $0.0005^{* * *}$ & 5 & 5 & 5 & 13 & 12 & 14 & 8.55 & 8.62 & 8.00 & 0.0019 ** & $0.0002^{* * * *}$ & $0.0125^{*}$ \\
\hline
\end{tabular}

fect of oily propolis was statistically significant by the introduction of methanol and dimethyl sulfoxide. Propolis is a non-toxic antimicrobial preparation affecting Grampositive and Gram-negative bacteria [1]. Active substances in propolis have an antimicrobial and antibacterial effect [1]. In recent studies, usage of propolis oily extract compare to ethanolic extract is very limited and it was used for antitumor activity [7] and humoral immunity stimulation mostly $[8,9]$. Our study is important for four major reasons; first we used three different diluents including DMSO, methanol and ethanol. Second, test was performed on different standard strains ATCC (American type culture collection) and resistance bacteria about in 14 different strains. Third, three suspension in different dilutions was used to evaluate bactericidal effect of oily propo- lis in different bacteria count suspensions and Forth, the effect of propolis dilutions with ethanol, methanol and DMSO on bacteria suspensions was evaluated. The purpose of this study was to verify the activity of an oily liquid extract of propolis called propolis extract in oil (B Natural. Italy) against some Gram-positive and Gram-negative bacteria. The active substance of propolis that used in this study was introduced in the forms of propolis extract in oil, the only liquid form of propolis that could be replaced with other solid forms. In literature, 70\% ethanol was used as the diluent for propolis. Due to ethanol is natural antibacterial activity, the evaluation of only propolis without diluent anti-bacterial effect is impossible. On the other hand, non-alcoholic diluent including dimethyl sulfoxide (DMSO) is suitable for some alcoholic limitation 


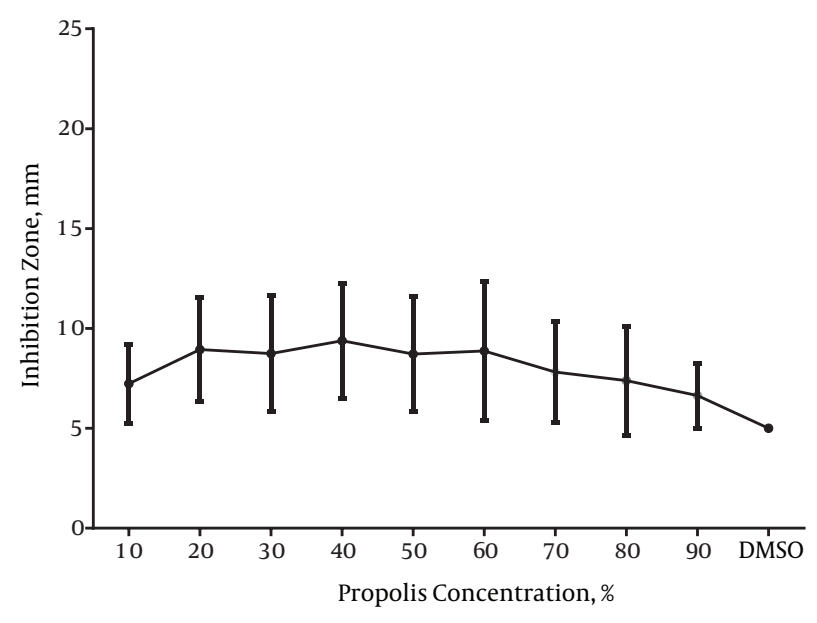

Figure 4. Inhibition Zone for Propolis with DMSO as Diluent in Different Concentrations from 10\% (10\% Propolis with 90\% DMSO) to 90\% (90\% Propolis with 10\% DMSO) and Pure DMSO as Control

Figure 5. Inhibition Zone Bacteria Against Propolis with Methanol in Different Concentration of Propolis from $10 \%$ to $90 \%$

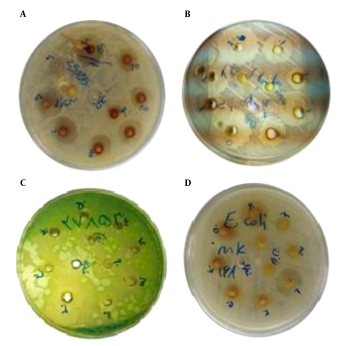

(A), Staphylococcus aureus ATCC 25923; (B), Enterococcus faecalis ATCC 29212; (C), Pseudomonas aeruginosa ATCC 27853; (D), Escherichia coli MK148 (AmpC $\beta$-lactamase positive).

Figure 6. Inhibition Zone Bacteria Against Propolis with DMSO in Different Concentration of Propolis from $10 \%$ to $90 \%$

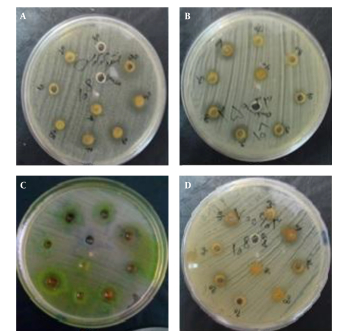

(A), Enterococcus faecalis ATCC 29212; (B), Staphylococcus aureus ATCC 25923; (C), Pseudomonas aeruginosa ATCC 27853; (D), Klebsiella pneumoniae ATCC 700603).

or diabetic patients and in some papers was noted that propolis activity was developed by DMSO diluent [10]. Our results showed that in the agar diffusion test with paper disks no growth inhibition zone was seen around control disks with methanol that is confirmed by Sawaya et al. [4]. The results of the study showed that the strongest effect against different type of bacteria was demonstrated by dilution $20 \%$ and $60 \%$ by diluent in methanol and DMSO, respectively, while the least potent effect for both diluents were seen in dilution $90 \%$ and $80 \%$ that the none of bacteria shown any inhibition zone. Attention to amount of oily propolis in dilution, methanol as diluent cause less amount of propolis and more bactericidal effect compare to DMSO, while recent paper indicated DMSO has more effect [10]. Some studies indicated Gram-negative bacteria, such as Pseudomonas aeruginosa was resistance to the bactericidal effect of propolis, but the determined inhibitory zone indicated that both Gram-positive and negative bacteria are sensitive to the studied propolis preparations, even Gram-negative bacteria are more sensitive. The evaluation of the examination results showed that the effectiveness of the extract against bacteria may be explained by the fact that the effect of propolis was statistically significant by the introduction of methanol and DMSO into the investigated emulsion systems $20 \%-40 \%$ and $40 \%-60 \%$, respectively. The results of the investigations also showed that the effect of the dilution containing $20 \%$ of propolis was similar to that of dilution $40 \%$, which contained $40 \%$ of propolis liquid. The comparison of dilution containing methanol alone (control negative) with dilution containing propolis liquid alone (control) showed any inhibition zone and any effect on the studied microorganisms; the findings also showed that increasing methanol percentage significantly $(\mathrm{P}<0.001)$ increased the potency of the propolis dilution while it doesn't change for DMSO dilution. With methanol the most inhibition effect of propolis was observed in dilution 40 , containing $40 \%$ of propolis in the form of liquid and 60\% pure methanol. It is noteworthy that all the investigated dilution specimens inhibited the growth of standard cultures of Gramnegative and Gram-positive microorganisms: Staphylococcus aureus (ATCC 25923) and Escherichia coli (ATCC 25922). For instance, the growth of Escherichia coli (ATCC 25922) was most strongly inhibited by dilution $10 \%$ to $30 \%$, and the weakest inhibition was observed in dilution 90\% (P> 1.00), which contained $10 \%$ of methanol. The growth of Staphylococcus aureus (ATCC 25923) was more efficiently inhibited by dilution $10 \%$ to $40 \%(\mathrm{P}<0.001)$. The weakest effect was exhibited by preparations that contained $80 \%$ to $90 \%$ liquid extract (Table 2). Attention to the results, dilution containing less propolis (dilution 10\% - 50\%) in compare to dilution with $80 \%$ - $90 \%$ propolis are more efficient. The results of this study are opposite of the literature data indicating that Gram-positive bacteria are more sensitive 
to propolis, compared to Gram-negative bacteria. Many researchers had investigated the antibacterial activity of propolis and its extracts against Gram-positive and Gramnegative strains and they found that propolis had antibacterial activity against a wide range of Gram-positive rods but had a limited activity against Gram-negative bacilli [5]. These kinds of differences in susceptibility among the microorganisms against antimicrobial substances in plant extracts may be explained by the differences in cell wall composition [11]. In our result shigella sonnei/ flexneri and Escherichia coli from Gram-negative bacilli group showed suitable sensitiveness to this novel propolis solution that in contrast of other result is very interesting. Although many studies determined propolis activity at higher concentrations was mainly bacteriostatic and bactericidal [12], our result indicated $20 \%-40 \%$ of propolis suspension with methanol have the most efficacy. So this novel form of liquid propolis can be used widely because of less amount of solution with more bactericidal effect. The present study has shown propolis antimicrobial activity against the following periodontal pathogens [13]: antimicrobial activity against Pseudomonas aeruginosa and Escherichia coli was also demonstrated in this study, confirming previous results [13]. Different results were achieved by Nieva et al. [14] that reported antimicrobial activity against Staphylococcus aureus, but no action against Pseudomonas aeruginosa and Escherichia coli. A possible explanation for diverse results is the fact that propolis composition is variable depending on the region and season that it is collected [13].

\section{Acknowledgments}

The authors would like to thank Shahid Sadoughi University of Medical Sciences and Tehran University of Medical Sciences for their support.

\section{Footnotes}

Conflict of Interests: The authors declare no conflicts of interest.

Funding/Support: The study was performed with the purpose of "General Health" Promotion and program designed to improve skin care techniques and researches in the field of "skin care advances" supported by Rejuline Group.

\section{References}

1. Ramanauskiene K, Inkeniene AM, Savickas A, Masteikova R, Brusokas V. Analysis of the antimicrobial activity of propolis and lysozyme in semisolid emulsion systems. Acta Pol Pharm. 2009;66(6):681-8. [PubMed: 20050532]

2. Banskota AH, Tezuka Y, Kadota S. Recent progress in pharmacological research of propolis. Phytother Res. 2001;15(7):561-71. doi: 10.1002/ptr.1029. [PubMed: 11746834].

3. Buriol L, Finger D, Schmidt EM, Santos JM, Rosa MRD, Quináia SP, et al. Chemical composition and biological activity of oil propolis extract: an alternative to ethanolic extract. Química Nova. 2009;32(2):296-302. doi: 10.1590/s0100-40422009000200006.

4. Sawaya AC, Souza KS, Marcucci MC, Cunha IB, Shimizu MT. Analysis of the composition of Brazilian propolis extracts by chromatography and evaluation of their in vitro activity against gram-positive bacteria. Brazilian Journal of Microbiology. 2004;35(1-2):104-9. doi: 10.1590/s1517-83822004000100017.

5. Khalil ML. Biological activity of bee propolis in health and disease. Asian Pac J Cancer Prev. 2006;7(1):22-31. [PubMed: 16629510].

6. Yaghoubi M, Ghorbani GR, Satari R. Antimicrobial activity of Iranian propolis and its chemical composition. DARU. 2007;15(1):45-8.

7. Carvalho AA, Finger D, Machado CS, Schmidt EM, Costa PM, Alves APNN, et al. In vivo antitumoural activity and composition of an oil extract of Brazilian propolis. Food Chem. 2011;126(3):1239-45. doi: 10.1016/j.foodchem.2010.12.035.

8. Taheri HR, Rahmani HR, Pourreza J. Humoral immunity of broilers is affected by oil extracted propolis (OEP) in the diet. Int J Poult Sci. 2005;4(6):414-7. doi: 10.3923/ijps.2005.414.417.

9. Ammar E, Gameil N, Nader M, Shawky N. Chinese Propolis Attenuates. Vivo. .

10. Netikova L, Bogusch P, Heneberg P. Czech ethanol-free propolis extract displays inhibitory activity against a broad spectrum of bacterial and fungal pathogens. J Food Sci. 2013;78(9):M1421-9. doi: 10.1111/1750-3841.12230. [PubMed: 23915150].

11. Karaman I, Sahin F, Gulluce M, Ogutcu H, Sengul M, Adiguzel A. Antimicrobial activity of aqueous and methanol extracts of Juniperus oxycedrus L. J Ethnopharmacol. 2003;85(2-3):231-5. doi: 10.1016/S03788741(03)00006-0. [PubMed: 12639746].

12. Drago L, De Vecchi E, Nicola L, Gismondo MR. In vitro antimicrobial activity of a novel propolis formulation (Actichelated propolis). J Appl Microbiol. 2007;103(5):1914-21. doi: 10.1111/j.1365-2672.2007.03421.x. [PubMed: 17953601].

13. Gebara ECE, Lima LA, Mayer MPA. Propolis antimicrobial activity against periodontopathic bacteria. Braz J Microbiol. 2002;33(4):365-9. doi: $10.1590 /$ s1517-83822002000400018.

14. Nieva Moreno MI, Isla MI, Cudmani NG, Vattuone MA, Sampietro AR Screening of antibacterial activity of Amaicha del Valle (Tucuman, Argentina) propolis. J Ethnopharmacol. 1999;68(1-3):97-102. [PubMed: 10624867]. 